\title{
Study on Pavement Performance of Foamed Asphalt Mixture in Mid-Surface of Expressway
}

\author{
Kejia Liu ${ }^{1, a}$, Bin Liang ${ }^{1, b}$ \\ Civil Engineering School, Henan University of Science and Technology, Luoyang 471023, China \\ a154966973@qq.com, bliangbin4231@163.com
}

Key words: foam asphalt mixture; water stability; durability; degree of compaction

Abstract. Pavement performance of Foamed Asphalt Mixture in Mid-Surface of Expressway is studied in the paper. The production process of foamed asphalt mixture in the construction site mixing station is briefly introduced. Experimental study on water stability of asphalt mixture by immersion Marshall test and freeze-thaw splitting test to improving the water stability of foamed asphalt mixture Introduction. Through the freeze-thaw cycle test, the durability of foamed asphalt mixture under the condition of multiple freeze-thaw cycles was studied. Combined with the actual engineering plant production of foam asphalt mixture and paving test section, the core of the test section of the sampling method to determine the compaction degree of two kinds of mixture pavement. The results show that there is little difference between the foam asphalt mixture and the hot mix asphalt mixture, and both of them can meet the technical requirements.

\section{Introduction}

Production of compressed air and water droplets by asphalt foaming equipment formed a combination of steam bubble. Steam bubble with hot asphalt, the combination of hot asphalt under the effect of surface tension in the form of thin film shape fully wrapped by steam bubble[1]. The foamed asphalt is sprayed into the mixing cylinder and then mixed with the hot aggregate to form the foam asphalt mixture[2]. Compared with conventional asphalt, the viscosity of foam asphalt is reduced, and the workability is increased. The foam asphalt can be fully wrapped in the lower temperature[3,4]. Application of foamed asphalt technology can effectively reduce the mixing temperature of asphalt mixture, so as to reduce energy consumption, to achieve energy saving more than $30 \%$, reduce $\mathrm{CO} 2$ emissions by more than $50 \%$.

In this paper, a comparative test is carried out to analyze the effect of warm mix SBS foam asphalt mixture and hot mix SBS modified asphalt mixture. Water immersion Marshall test and freeze-thaw split test were carried out to study the stability of two kinds of mixture, and to evaluate its ability of resist water damage; The freeze-thaw cycle test was carried out to study its low temperature durability; The core compaction method is used to evaluate the compaction quality of road surface.

\section{Project Profile}

Deshang expressway construction started in October 2012, the total length of $68.9 \mathrm{~km}$. Xiajin to Liaocheng road engineering section of the highway construction standard. The expressway design speed $120 \mathrm{~km} / \mathrm{h}$, two-way four lane, roadbed width of $28 \mathrm{~m}$, flexible base half width of $11.75 \mathrm{~m}$, compaction thickness of $6 \mathrm{~cm}$ The section of the project was officially opened in July 28, 2016. Based on the expressway engineering, 200m foam asphalt mixture was tested at the entrance of Xiajin. It was compared with the conventional hot mix technology section to research the application performance of foamed asphalt mixture. 


\section{Production technology}

In the asphalt foaming equipment, using flow meter to control the foaming water consumption is $1 \%$. In order to better ensure the foaming effect of asphalt, asphalt still needs a higher heating temperature. Therefore, the heating temperature of foamed asphalt is $165^{\circ} \mathrm{C}$, which is the same as that of hot mix asphalt. The half-life and expansion rate of foamed asphalt are better at this temperature. The hot asphalt, which is combined with the high pressure water vapor generated by the foaming equipment, becomes the foam asphalt. The foam asphalt is sprayed into the mixing tank and heat aggregate mixed with mineral powder mixing made of foamed asphalt mixture. Mixing plant production of foam asphalt concrete process is shown in Fig.1.

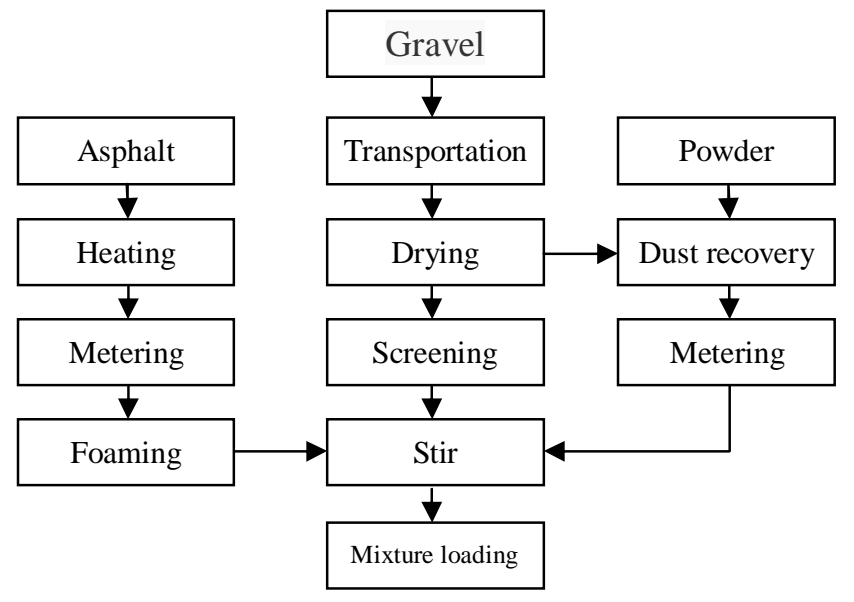

Fig.1 Production process of foamed asphalt mixture

The temperature parameters of each production stage of warm SBS foam asphalt mixture and hot SBS modified asphalt mixture are shown in Tab.1.

Tab.1 Production temperature of asphalt mixture

\begin{tabular}{|c|c|c|c|c|}
\hline Type & Asphalt $/{ }^{\circ} \mathrm{C}$ & Aggregate $/{ }^{\circ} \mathrm{C}$ & Mixing $/{ }^{\circ} \mathrm{C}$ & compaction $/{ }^{\circ} \mathrm{C}$ \\
\hline HMA & 165 & 195 & 185 & 175 \\
\hline WMA & 165 & 170 & 160 & 150 \\
\hline
\end{tabular}

\section{Water stability research}

Immersion Marshall test. According to the regulations of T0702 forming the standard Marshall specimen, measuring the physical index, then put it in the constant temperature of $60^{\circ} \mathrm{C}$ water bath box in maintenance, after the $48 \mathrm{~h}$ test on it. The results of immersion Marshall test are shown in Tab.2.

Tab.2 Immersion Marshall test results

\begin{tabular}{|c|c|c|c|c|c|}
\hline Type & Air void/\% & $\mathrm{MS}_{0} / \mathrm{KN}$ & $\mathrm{MS}_{1} / \mathrm{KN}$ & Residual stability/\% & Requirement \\
\hline HMA & 4.4 & 14.00 & 12.10 & 86.4 & $\geq 85$ \\
WMA & 5.3 & 13.83 & 11.85 & 85.7 & \\
\hline
\end{tabular}

The residual stability of foam asphalt mixture is $85.7 \%$. Compared with hot mix $86.4 \%$ decreased by $0.9 \%$, the degree of decline was smaller. The stability of foam asphalt mixture before soaking and the stability of $48 \mathrm{~h}$ after soaking were decreased by $0.17 \mathrm{kn}$ and $0.25 \mathrm{kn}$ compared with 
that of hot mix mixture, and the degree of decline of the three data was small. The residual stability of both can meet the requirement of the specification is more than $85 \%$.

Freeze-thaw splitting test. On the highway construction site require a higher degree of compaction, the freeze-thaw splitting test specimen used by compaction 75 times molding standard Marshall specimen. After the vacuum $97.3 \mathrm{Kpa}$ of water under the pressure of $15 \mathrm{~min}$, the specimen was frozen $16 \mathrm{~h}$ in the constant temperature test box at $-18^{\circ} \mathrm{C}$, and then was placed in a constant temperature tank of $60^{\circ} \mathrm{C}$ for in the temperature of $24 \mathrm{~h}$. After $2 \mathrm{~h}$ immersion in the $25^{\circ} \mathrm{C}$ constant temperature tank, the splitting test was carried out. The results of freeze-thaw splitting test are shown in Tab.3.

Tab.3 Results of freeze-thaw splitting test

\begin{tabular}{|c|c|c|c|c|c|}
\hline Type & $\begin{array}{c}\text { Bitumen } \\
\text { aggregate ratio /\% }\end{array}$ & $\begin{array}{c}\text { Strength before } \\
\text { freeze /MPA }\end{array}$ & $\begin{array}{c}\text { Strength before } \\
\text { freeze /MPA }\end{array}$ & $\begin{array}{c}\text { Splitting strength } \\
\text { ratio /\% }\end{array}$ & Requirement \\
\hline HMA & 4.6 & 1.19 & 1.08 & 90.8 & $\geq 80$ \\
\hline WMA & 4.6 & 1.14 & 0.98 & 86.0 & \\
\hline
\end{tabular}

Because of the warm mix asphalt mixture foam porosity is relatively large, the splitting strength was slightly lower than the hot mix asphalt mixture, The freeze-thaw splitting strength decreased by $0.1 \mathrm{MPa}$. Due to the volume expansion of asphalt mixture in the free water after freezing. The void ratio of two kinds of mixture increases with the increase of internal tension, and the splitting strength ratio of foamed asphalt mixture is lower than that of hot mix asphalt $4.8 \%$, However, the splitting strength ratio of both is greater than $80 \%$ of the technical requirements.

\section{Durability research}

Freeze-thaw splitting test is only a single freeze-thaw cycle, the purpose is to enlarge the impact of water damage on the mixture, so as to study the water stability of asphalt mixture. The freeze-thaw cycle test specimen by vacuum water saturated, at $-18^{\circ} \mathrm{C}$ after $16 \mathrm{~h}$ freezing, and then placed in $25^{\circ} \mathrm{C}$ constant temperature water bath for $12 \mathrm{~h}$. In this cycle, 5 cycles were used to evaluate the durability of the mixture. The results of freeze-thaw cycle test are shown in Tab.4.

Tab.4 Results of freeze-thaw cycle test

\begin{tabular}{|c|c|c|c|c|c|c|}
\hline \multirow{2}{*}{$\begin{array}{l}\text { Cycle } \\
\text { times }\end{array}$} & \multicolumn{3}{|c|}{ HMA } & \multicolumn{3}{|c|}{ WMA } \\
\hline & Air void $1 \%$ & Strength /Mpa & Ratio $/ \%$ & Air void $1 \%$ & Strength /Mpa & Ratio $/ \%$ \\
\hline 0 & 4.4 & 1.167 & l & 5.3 & 1.140 & I \\
\hline 1 & 4.9 & 1.059 & 90.8 & 5.8 & 1.012 & 88.8 \\
\hline 2 & 5.2 & 1.012 & 95.6 & 6.4 & 0.954 & 94.3 \\
\hline 3 & 5.6 & 0.969 & 95.8 & 7.0 & 0.912 & 95.6 \\
\hline 4 & 5.8 & 0.929 & 95.9 & 7.3 & 0.890 & 97.6 \\
\hline 5 & 6.1 & 0.887 & 95.5 & 7.6 & 0.872 & 97.9 \\
\hline
\end{tabular}

The splitting strength of the first cycle was $86 \%$ higher than that of the freeze-thaw splitting test, but there was no effect on the HMA. With the increase of air void freeze thawing, two kinds of mixture after the first freeze-thaw strength is greatly reduced, the splitting strength ratio of HMA is 
$90.8 \%$, while WMA is $88.8 \%$. After 2 to 3 cycles, the strength of the mixture tends to be stable. The splitting strength ratio of HMA after repeated freeze-thaw stability in more than $97 \%$, worm mixture stabilized at more than $95 \%$, the foam asphalt mixture decreased $2 \%$ compared to hot mix, visible foam asphalt mixture in the long-term durability of repeated freezing and thawing slightly lower than the hot mix asphalt mixture, but little difference still meet road requirements.

\section{Road surface compaction degree research}

The four core points of the test road were tested by using the core drilling machine. The density of asphalt mixture core sample was measured by Drilling Core method, and the compaction degree of asphalt surface was measured. The results of compaction degree are shown in Tab.5.

Tab.5 Test results of compaction degree of Asphalt Pavement

\begin{tabular}{|c|c|c|c|c|c|c|}
\hline Type & Number & Density & $\begin{array}{l}\text { Theoretical } \\
\text { compaction } / \%\end{array}$ & $\begin{array}{l}\text { Representative value } \\
\qquad \mathrm{K}_{1} / \%\end{array}$ & $\begin{array}{c}\text { Standard compaction } \\
1 \%\end{array}$ & $\begin{array}{c}\text { Representative value } \\
\mathrm{K}_{2} / \%\end{array}$ \\
\hline \multirow{2}{*}{ HMA } & 1 & 2.368 & 93.3 & \multirow{2}{*}{$92.3 \geq 92$} & 97.3 & \multirow{2}{*}{$96.3 \geq 96$} \\
\hline & 2 & 2.382 & 93.9 & & 97.9 & \\
\hline \multirow{2}{*}{ WMA } & 3 & 2.353 & 92.7 & \multirow{2}{*}{$92.2 \geq 92$} & 98.1 & \multirow{2}{*}{$97.6 \geq 96$} \\
\hline & 4 & 2.347 & 92.5 & & 97.9 & \\
\hline
\end{tabular}

The compaction degree of two kinds of mixture can meet the specification requirements. The pavement compaction temperature of HMA is higher than that $25^{\circ} \mathrm{C}$ of the WMA, but due to the reduction of foam asphalt viscosity, so that the mixture can be compacted at low temperature and meet the specification requirements.

\section{Conclusion}

The application of foam warm mix technology in the production process of the mixture decreased the average heating temperature of $20 \sim 30^{\circ} \mathrm{C}$, the foam asphalt mixture can effectively reduce the viscosity of mixing and compaction.

The water stability of foamed asphalt mixture decreases, but the performance still meets the requirements of the specification. The splitting tensile strength of foam asphalt mixture slightly lower than the hot mix asphalt mixture, but remained at a high level. The construction compaction degree of foam asphalt mixture is basically the same as that of hot mix asphalt mixture, which is in full compliance with the standard requirements for compaction degree.

\section{References}

[1] F.J. Shi, W.M. Lv, Principle and study of Bitumen Foaming, J. Journal of building materials. 2(2004)183-185. ( In Chinese)

[2] Y.H. Yang, X. Yao, Experimental Investigation of Workability for Asphalt Mixtures, J, Materials Review.27(2013)308-310.(In Chinese)

[3] Z.L. Li, X.J. Ding, Environment protection in application of asphalt mixture, J. Journal of Traffic and Transportation Engineering.4(2004)1-4. (In Chinese) 
[4] L.F. Shi, Effects of Molding Temperature on Properties of Foamed Warm-mixed Asphalt Mixture, J, Highway Engineering. 40(2015)250-253. (In Chinese) 